International Journal of Advanced Chemistry, 9(2)(2021) 161-167
International Journal of Advanced Chemistry
SPC
Website: www.sciencepubco.com/index.php/IJET
Research paper

\title{
Detection of interaction between ornidazole and albumin by using thermodynamic parameters
}

\author{
Esra Maltas Cagil * \\ Division of Biochemistry, Department of Basic Pharmacy Sciences, Faculty of Pharmacy, Selcuk University, Konya 42031, Turkey \\ *Corresponding authorE-mail: esramaltas@gmail.com
}

\begin{abstract}
The binding of 1-chloro-3-(2-methyl-5-nitro-1H-imidazole-1-yl) propan-2-ol (Ornidazole) to human serum albumin (HSA) was studied by fluorescence and UV-visible spectroscopy. Interaction of ornidazole (OR) with HSA was identified by Stern-Volmer and Van't Hoff equations. The binding constant, $\mathrm{Kb}$ and the thermodynamic parameters, $\Delta \mathrm{H}, \Delta \mathrm{S}$, and $\Delta \mathrm{G}$ at different temperatures were calculated by several equations. Data shows that the fluorescence quenching mechanism of HSA with ornidazole may occur via static quenching. The thermodynamic parameters showed that van der Waals interactions and hydrogen bonds are the major forces for the interaction of ornidazole with HSA. The spectral changes of synchronous fluorescence suggested that both the microenvironment of OR and the conformation of HSA concerning their concentrations have changed during binding.
\end{abstract}

Keywords: Ornidazole; Human Serum Albumin (HSA); Fluorescence Quenching; Stern Volmer Equation; Thermodynamic Parameter.

\section{Introduction}

Albumin is the main protein for the transportation of a wide variety of substances like metals, fatty acids, amino acids, hormones, and a large list of drugs [1]. Amino acids number and sequences of the albumins from different sources are well known. Therefore, albumin is widely used in the studies of interactions between drugs and proteins in vitro. Database related to the albumin leads to ease of explaining the binding mechanism of albumin to any substances. Several types of albumin which are from human, rat, and bovine are the most commonly studied proteins to identify the interaction between proteins and drugs for many decades. However, the tridimensional structure is only available for human serum albumin (HSA). HSA contains about 580 amino acid residues in a single polypeptide chain with a molecular weight of $67,000 \mathrm{Da}$ [2]. HSA has $67 \%$ of alpha-helix with six turns and 17 disulfide bridges in the secondary structure [3-4]. The rest of the chain is composed of an extended peptide chain with $10 \%$ of $\beta$ turns. The X-ray crystal structure of HSA shows three homologous domains (I, II, and III). Each domain includes two subdomains (IA and B, IIA and B, IIIA and B) which possess structural patterns. Ligands bind to two subdomains, IIA and IIIA in Sudlow site I and Sudlow site II. These sites have hydrophobic cavities [5-7]. A lot of Tyr residues, from 18 to 21 depending on the species are involved in the sequence of HSA. A single Trp residue appears as Trp214 in the sequence of HSA [2].

A large number of drugs and bioactive molecules bind reversibly to all types of albumin [8-13]. Albumin usually increases the solubility of hydrophobic drugs in plasma and serum, which is a very important protein for the drug delivery to target cells in vivo and in vitro [14]. The knowledge of the reaction between a drug molecule and albumin is useful for interpreting the pharmacokinetics and transport of the drugs. Particularly, the structural and energetic aspects of the interaction provide knowledge to understand interaction mechanisms for the further development of new therapeutic agents [15-16].

Ornidazole which is one of the 5-nitroimidazole derivatives belongs to a group of medicines called antiprotozoal. It is used to treat infections caused by protozoa such as amoebiasis, trichomoinasis. It is also used in the poultry industry [17-18]. The efficacy and safety of ornidazole, as a nitroimidazole antibiotic, has been investigated for use in Crohn's disease which almost inevitably recurs after ileocolonic resection, and effective prophylactic therapy has not been identified. However, an important side effect of ornidazole is well known. Ornidazole is a type of concomitant administration of oral anticoagulants which may increase the risk of hemorrhage due to diminished hepatic metabolism [19-21]. Fluorescence spectroscopy is a powerful tool for the investigation of the reaction of drugs with proteins and makes it possible to analyze the spectrum of a protein at specific excitation and emission wavelengths [15-16]. In the present work, we demonstrated the binding of ornidazole to human serum albumin by using fluorescence and UV-Visible spectroscopy. The nature of the binding of the drugs with the proteins were described by using the Stern Volmer equation. Synchronous fluorescence was also used to estimate environmental changes of HSA corresponding to interaction. This work aimed to determine the affinity of ornidazole to HSA and to investigate the thermodynamic parameters of their interaction. 


\section{Materials and methods}

Materials: 1-chloro-3-(2-methyl-5-nitro-1H-imidazole-1-yl) propan-2-ol (Ornidazole), $\mathrm{HCl}, \mathrm{NaOH}$, albumin from human serum (97-99\%), ethanol, and Tris (hydroxymethyl) aminomethane were purchased from Sigma-Aldrich (USA). The ultra-pure water was purified by the Milli-Q water purification system (Millipore, Bedford, MA, USA). All reagents and chemicals were of molecular and analytical grade. Apparatus: All fluorescence measurements were done by a Perkin Elmer LS-55 spectrofluorometer (Perkin Elmer, USA) equipped with a xenon lamp source and a $1.0 \mathrm{~cm}$ quartz cell. Absorption spectra were recorded on a Shimadzu-1700 UV-visible spectrophotometer (Shimadzu, Kyoto, Japan) using a $1.0 \mathrm{~cm}$ quartz cell.

Fluorescence spectroscopy: Ornidazole (OR) (Scheme 1) was prepared as $1 \mathrm{mM}$ of stock solution in a water-ethanol solvent system (V:V, $50: 50 \%$ ) for all experiments. $0.1 \mathrm{mM}$ of HSA solution was prepared by directly dissolving the protein in a Tris buffer including $20 \mathrm{mM}$ of Tris at $\mathrm{pH}$ of 7.4. All aqueous solutions using in testing contained 5\% (v/v) ethanol for all measurements. An appropriate volume of OR solution was added to HSA ranging from $1 \mu \mathrm{g}$ to $20 \mu \mathrm{g}$, then mixed for 10 minutes at RT. The fluorescence spectra from 200 to $500 \mathrm{~nm}$ were scanned by fluorescence spectroscopy using the $10 \mathrm{~nm}$ of slit in a quartz cell. The appropriate volume of HSA (10 $\mu \mathrm{g})$ was mixed with different amounts of OR ranging from 1 to $80 \mu \mathrm{M}$ and then, diluted to $2.0 \mathrm{~mL}$ with the Tris buffer. The fluorescence spectra were collected with the excitation wavelength at $280 \mathrm{~nm}$.<smiles>Cc1ncc([N+](=O)[O-])n1CC(O)CCl</smiles>

Scheme 1: Structure of ornidazole.

Synchronous fluorescence spectroscopy: Appropriate volume of HSA in the Tris buffer was mixed with OR at a concentration range between 1 and $80 \mu \mathrm{M}$. The fluorescence spectra were recorded at the $\Delta \lambda=15 \mathrm{~nm}$ and $\Delta \lambda=60 \mathrm{~nm}$ for all OR-HSA.

Absorption of OR against HAS: The appropriate volume of HSA in $20 \mathrm{mM}$ of Tris buffer (pH:7.4) was added to different amounts of OR ranging from 5 to $60 \mu \mathrm{M}$. Absorption spectra of the solution were collected by Shimadzu $1700 \mathrm{UV}$-visible spectrophotometer (Shimadzu, Kyoto, Japan).

\section{Results and discussion}

Fluorescence quenching: A good linear response of fluorescence intensity concerning to HSA concentrations was also obtained at $280 \mathrm{~nm}$ of excitation and $342 \mathrm{~nm}$ of emission wavelengths. The linear equation is IF $=10.969 \mathrm{HSA}-27.146 \times 10^{-6}(\mathrm{R}=0.9965)$ while the concentration of HSA ranging from 1 to $20 \mu \mathrm{g}$. The emission spectra of HSA at a fixed concentration of OR $(20 \mu \mathrm{M})$ were done in $20 \mathrm{mM}$ of Tris buffer ( $\mathrm{pH}$ 7.4) and is presented in Fig. 1. Interaction of OR with HSA results in enhancement of the fluorescence intensity with a slight blue shift at 280 of excitation wavelength when amounts of HSA enhanced. The blue shift means a decrease in the polarity of the microenvironment of OR. This result suggests that an interaction between OR and HSA occurs in the hydrophobic microenvironment of HSA.

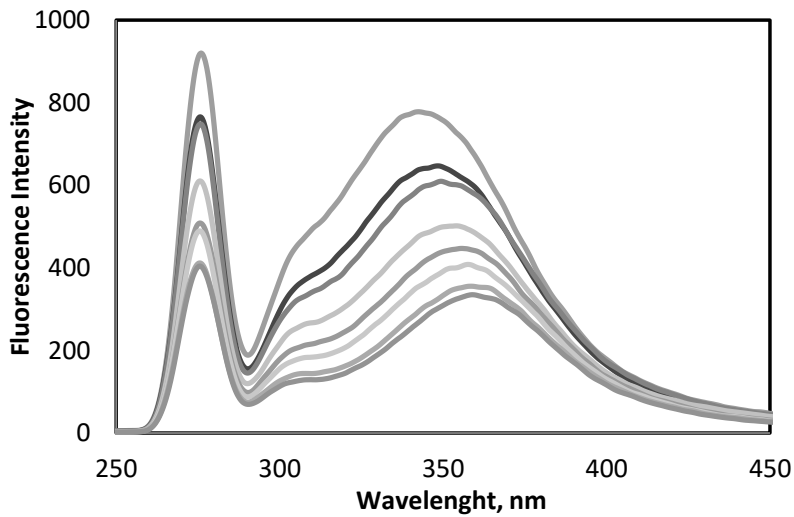

Fig. 1: Fluorescence Spectrum of HSA at A Fixed Concentration of Ornidazole $(\mathrm{T}=296 \mathrm{~K}, \lambda \mathrm{Ex}=280 \mathrm{Nm})$. [OR]: $20 \mu \mathrm{m},[\mathrm{HSA}]: 20,15,12.5,10,7.5,5$, 2.5 and $1 \mathrm{Mg}$.

The fluorescence intensity of HSA decreased and the emission band exhibited a slight red shift when the amounts of OR were increased. The fluorescence intensity of HSA regularly decreased with an increase in OR concentration ranging from 1 to $80 \mu \mathrm{M}$, as shown in (Fig. 2). The red shift of the maximum emission can prove the changes in the residues' surrounding environments in polarity which is increased, suggesting the decrease in hydrophobicity and extension of HSA molecule [22-23]. 


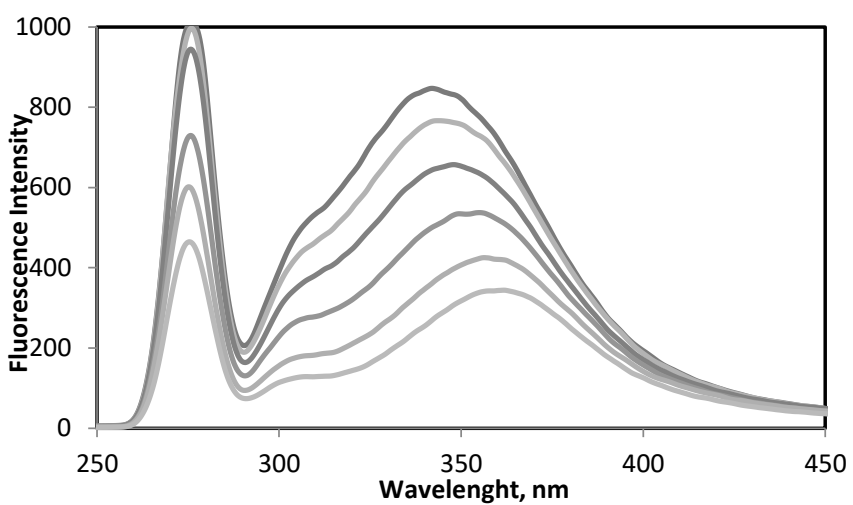

Fig. 2: Fluorescence Spectrum of HSA $(10 \mathrm{Mg})$ at Different Concentrations of Ornidazole $(\mathrm{T}=296 \mathrm{~K}, \lambda \mathrm{Ex}=280 \mathrm{Nm})$. [OR] = 5, $10,20,30,40,60$ and 80 $\mu \mathrm{m}$.

Synchronous fluorescence of HSA: It is well known that the fluorescence characteristic of protein results from the protein's tyrosine and tryptophan residues. The synchronous fluorescence spectrum gives the intrinsic fluorescence of the proteins related to tyrosine and tryptophan residues of which fluorescence is recorded at a specific wavelength, $\Delta \lambda$, between excitation and emission wavelengths. When $\Delta \lambda$ is set as $60 \mathrm{~nm}$, the synchronous fluorescence spectrum belongs to the characteristic information of the tryptophan residues. When set at 15 $\mathrm{nm}$, the characteristic spectrum of the tyrosine residues appears [22]. The fluorescence intensity of HSA with the addition of OR at a concentration range between 1 and $80 \mu \mathrm{M}$ was measured. Fig. 3a and Fig. 3b show that the fluorescence intensity of tyrosine residues $(\Delta \lambda=15 \mathrm{~nm})$ decreased with a slight blue shift while that of tryptophan residues $(\Delta \lambda=60 \mathrm{~nm})$ exert a slight red shift at the emission spectra with decrease in OR concentration. However, it is seen that the pitch of quenching at $\Delta \lambda 60 \mathrm{~nm}$ is higher than that of $\Delta \lambda 15 \mathrm{~nm}$ with the addition of OR (Fig. 4). OR molecule was presented to be closer to tryptophan residues than tyrosine residues. The result indicates that the binding sites are mainly on tryptophan moiety [23].
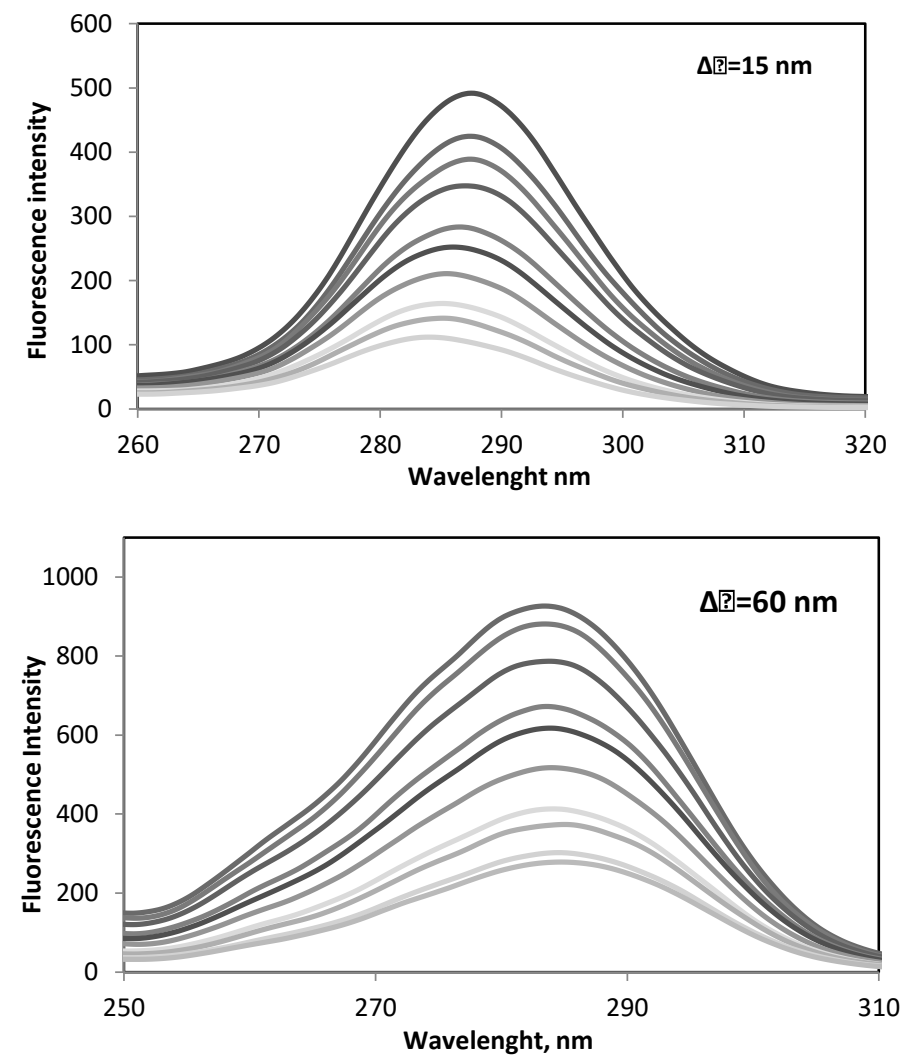

Fig. 3: (A) Synchronous Fluorescence Spectrum of HSA (10 Mg) in the Presence of Different Amount of Ornidazole with $\Delta \lambda=15$ Nm. (B) Synchronous Fluorescence Spectrum of HSA in the Presence of Different Amount of Ornidazole with $\Delta \lambda=60 \mathrm{Nm},[\mathrm{OR}]=1,4,8,10,20,30,40,50,60,70$ and $80 \mu \mathrm{m}$. 


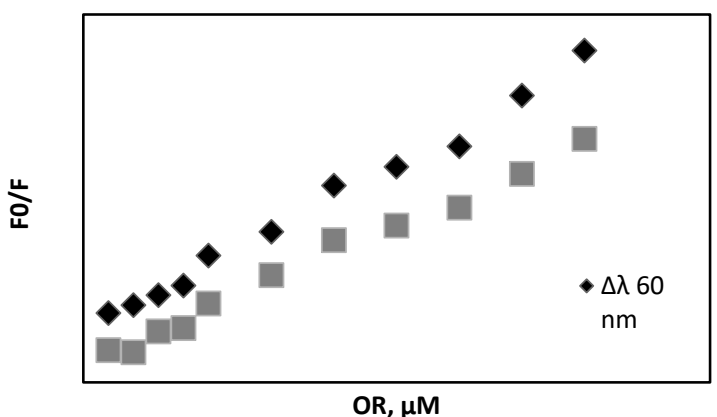

Fig. 4: The Quenching Degree of HSA (10 Mg) Synchronous Fluorescence by Ornidazole. [OR] =2, 4, 6, 8, 10, 15, 20, 25, 30, 35 and 40 $\mu$ m.

Binding Mechanism of OR and HSA: Reduction of the fluorescence intensity by any molecule is referred to as fluorescence quenching. A large number of molecular interactions which can lead to quenching are molecular rearrangements, excited-state reactions, energy transfer, complex formation, and collisional quenching. Quenching can occur via two mechanisms as dynamic and static quenching. Both quenching mechanisms depend on temperature and excited-state lifetime. Higher temperatures result in faster diffusion, thus larger amounts of collisional quenching. The fluorescence quenching is assumed to be a dynamic quenching process first to explain the binding mechanism of HSA by OR. The dynamic quenching mechanism is usually analyzed via the Stern-Volmer equation (Eq 1) as follows [23]

$\mathrm{F}_{0} / \mathrm{F}=1+\mathrm{K}_{\mathrm{q}} \tau_{0}[\mathrm{Q}]=1+\mathrm{Ksv}[\mathrm{Q}]$

Where $\mathrm{F}_{0}$ and $\mathrm{F}$ are the steady-state fluorescence intensities in the absence and the presence of quencher, Ksv is the Stern-Volmer quenching constant, and $[\mathrm{Q}]$ is the concentration of quencher. $\tau_{0}$ is the average biomolecules fluorescence lifetime which is known to be $10^{-8} \mathrm{~s}$ without the addition of quencher [24].

The Stern-Volmer plots at four temperatures are shown in Fig. 5. The values of Ksv and Kq at 296, 298, 303, and $308 \mathrm{~K}$ were calculated from the regression equations of which slopes are presented in Table $1 . \mathrm{K}_{\mathrm{q}}$ values were found to be 2.87, 3.14, 3.66, and 4.11 $\times 10^{12} \mathrm{~L} \mathrm{~mol}^{-1} \mathrm{~s}^{-1}$. Stern-Volmer plots for the quenching of HSA-OR at different temperatures. Ksv values were determined as $0.287,0.321$, 0.369 and $0.410 \times 10^{-5} \mathrm{~L} \mathrm{~mol}^{-1}$. Data indicate that the $\mathrm{K}_{\mathrm{q}}$ values are much larger than the maximum scattering collision quenching constant which is considered as $2.0 \times 10^{10} \mathrm{~L} \mathrm{~mol}^{-1} \mathrm{~s}^{-1}$ [25]. Higher $\mathrm{K}_{\mathrm{q}}$ values suggest that the interaction between OR and HSA may come from static quenching via forming complexes [26].

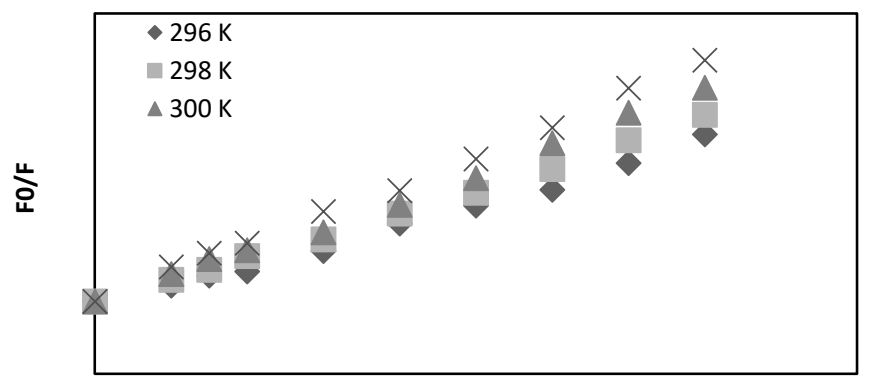

[OR] 105M

Fig. 5: Stern-Volmer Plots for the Quenching of HSA by OR at Different Temperatures.

UV-visible spectroscopy is a useful tool to explain structural changes in proteins and to study interactions between proteins and small molecules. The UV-visible spectral measurements also distinguish the quenching mechanisms as staticanddynamicquenching [22]. According to the principles of absorption spectroscopy, dynamic quenching is only induced by the excited states of the fluorophores. There is no change in absorption spectra, which suggests that absorption spectra of fluorescent molecules are not affected by a quencher. In contrast, static quenching is affected by the formation of ground-state complexes, lead to changes in absorption spectra [25-28]. In the range of 250-400 $\mathrm{nm}$ in Fig. 6, the absorption peak at $325 \mathrm{~nm}$ shows a slightly shift. Therefore, the fluorescence quenching between OR and HSA was mainly attributed to being static quenching. However, the absorbance corresponding to OR increased upon the addition of the HSA molecule. Because of this increase, an interaction between OR and HSA is considered to occur. So, peptide strands of HSA may be extended, resulting in a conformational change in the protein structure. 


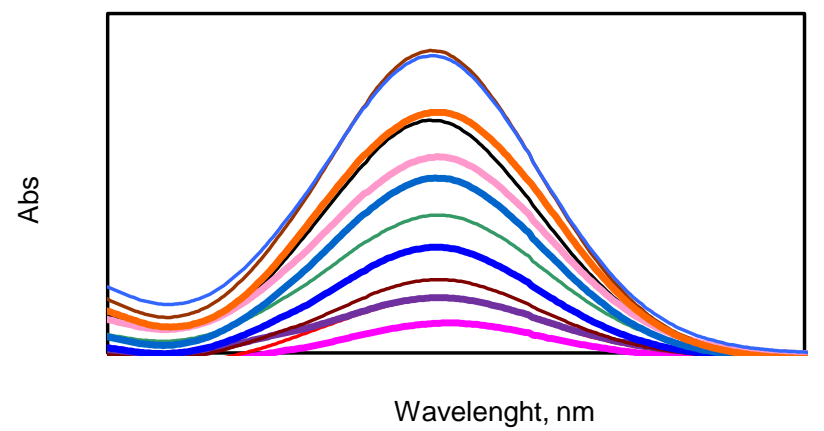

Fig. 6: Absorption Spectra of OR at Different Concentration in the Presence and Absence of HSA (10 Mg) at 5, $10,20,30$ 50, 60 Mm Free OR and ORHSA are Shown by Thick and Thin Lines, Respectively.

Analysis of binding equilibria: HSA is considered a biomacromolecules. OR binds independently on the equivalent sites of HSA. Therefore, the equilibrium between free and bound molecules is given by the equation (Eq 2) as follows [28]:

$\operatorname{Lg}\left(\mathrm{F}_{0}-\mathrm{F}\right) / \mathrm{F}=\lg \mathrm{K}_{\mathrm{b}}+\mathrm{nlg}[\mathrm{Q}]$

Where $\mathrm{K}_{\mathrm{b}}$ is the binding constant and $\mathrm{n}$ is the number of binding sites per protein. These values are estimated from Eq. 2 at different temperatures. The linear quantities are given in Table 1 and are larger than 0.99 , indicating that the assumptions underlying the derivation of Eq. 1 are satisfied. (Table 1) presents values of $\mathrm{K}_{\mathrm{b}}\left(2.18,1.77,1.41\right.$, and $\left.1.20 \times 10^{-3} \mathrm{~mol} \mathrm{~L}^{-1}\right)$ and $\mathrm{n}(1.46,1.41,1.36$ and 1.34$)$ which decreased with an increase in temperatures $(296,298,300$, and $302 \mathrm{~K}$ ) as viewed in Fig.7. This may be indicative for forming an unstable compound that would be partly decomposed when the temperature increased. Therefore, the values of $K_{b}$ and $n$ were low at high temperatures.

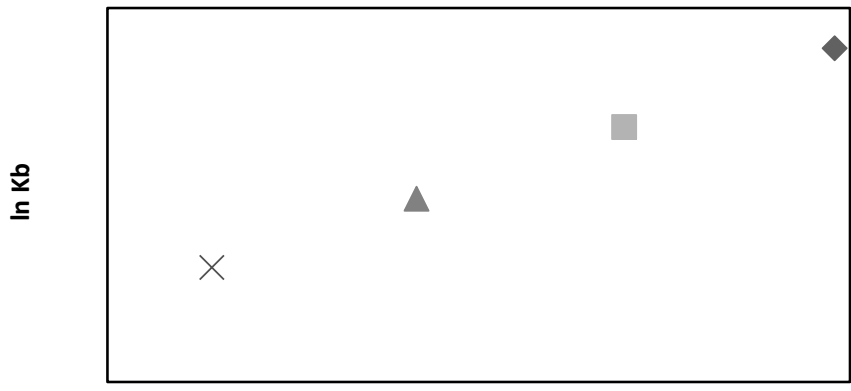

$1 / \mathrm{T}$

Fig. 7: Van't Hoff Plot for the Quenching of HSA by OR at Different Temperatures.

Table 1: Quenching and Binding Constant $\mathrm{K}_{\mathrm{b}}$ and Binding Sites $\mathrm{n}$ at Different Temperatures

\begin{tabular}{|c|c|c|c|c|c|c|}
\hline $\mathrm{pH}$ & $\mathrm{T}(\mathrm{K})$ & $\mathrm{K}_{\mathrm{b}}, \mathrm{M}$ & $\mathrm{n}$ & $\mathrm{R}^{\mathrm{a}}$ & $\mathrm{K}_{\mathrm{q}} \mathrm{L} \mathrm{mol}^{-1} \mathrm{~s}^{-1}$ & $\mathrm{Ksv} \mathrm{L} \mathrm{mol}^{-1}$ \\
\hline \multirow[t]{4}{*}{7,4} & 296 & $2.18 \mathrm{e}-3$ & 1.46 & 0.9910 & $2.87 \mathrm{e} 12$ & $296 \mathrm{e} 5$ \\
\hline & 298 & $1.77 \mathrm{e}-3$ & 1.41 & 0.9944 & $3.14 \mathrm{e} 12$ & $298 \mathrm{e} 5$ \\
\hline & 300 & $1.47 \mathrm{e}-3$ & 1.37 & 0,9913 & $3.66 \mathrm{e} 12$ & $300 \mathrm{e} 5$ \\
\hline & 302 & $1.20 \mathrm{e}-3$ & 1.34 & 0.9954 & $4.11 \mathrm{e} 12$ & $302 \mathrm{e} 5$ \\
\hline
\end{tabular}

(a) $\mathrm{R}$ is the linear quotiety.

Thermodynamic parameters and nature of the binding forces: Thermodynamic parameters provide an idea about the molecular mechanism of the interaction between OR and HSA. The thermodynamic parameters have been estimated from binding constants (K $\left.\mathrm{K}_{\mathrm{b}}\right)$ at four temperatures [29]. The Van't Hoff plot of $\ln \mathrm{K}_{\mathrm{b}} \mathrm{vs.} 1 / \mathrm{T}$ and Eq. 3 gives the thermodynamic parameters such as $\Delta \mathrm{G}, \Delta \mathrm{H}$, and $\Delta \mathrm{S}$ corresponding to this interaction. Enthalpy $(\Delta \mathrm{H})$ and entropy change $(\Delta \mathrm{S})$ can be determined from the following Van't Hoff equation (Eq s) [22]:

$$
\ln \mathrm{K}_{\mathrm{b}}=-\Delta \mathrm{H} / \mathrm{RT}+\Delta \mathrm{S} / \mathrm{R}
$$

Where $\mathrm{K}_{\mathrm{b}}$ is binding constant at the different temperatures, $\mathrm{R}$ is the gas constant; $\mathrm{T}$ is the experimental temperature [7], [8]. The free energy change $(\Delta \mathrm{G})$ is estimated from the following relationship (Eq. 4) [25]:

\section{$\Delta \mathrm{G}=\Delta \mathrm{H}-\mathrm{T} \Delta \mathrm{S}$}

Data at different temperatures (296, 298, 302, and $304 \mathrm{~K}$ ) are represented in Table 2. The slope and intercept of Van't Hoff plot give values of the enthalpy and entropy which are independent of temperature according to the basic assumption of Van't Hoff equation. The large negative changes in entropy and enthalpy $\left(\Delta \mathrm{S}=-100.56 \mathrm{~J} \mathrm{~mol}^{-1} \mathrm{~K}^{-1}\right.$ and $\left.\Delta \mathrm{H}=-0.44 \mathrm{~J} \mathrm{~mol}^{-1}\right)$ suggest that van der Waals interactions and hydrogen bonds are major forces for binding $[26,30]$. The free energy changes, $\Delta \mathrm{G}$ in different temperatures were calculated as $35.01(298$ $\mathrm{K}), 6.37(303 \mathrm{~K}), 6.17(308 \mathrm{~K})$, and $5.97 \mathrm{~kJ} \mathrm{~mol}^{-1}(304 \mathrm{~K})$. The values of $\Delta \mathrm{G}$ were positive at all experimental temperatures, indicating that the reaction is energy-dependence. The values of $\Delta \mathrm{H}$ and $\Delta \mathrm{S}$ are negative at the experimental temperatures, suggests that the van der Waals interactions and hydrogen bonds play major roles in the binding mechanism. 
Table 2: Relative Thermodynamic Parameters

\begin{tabular}{llllll}
\hline $\mathrm{pH}$ & $\mathrm{T}(\mathrm{K})$ & $\mathrm{R}$ & $\Delta \mathrm{H}\left(\mathrm{kj} \mathrm{mol}^{-1}\right)$ & $\Delta \mathrm{G}\left(\mathrm{kj} \mathrm{mol}^{-1}\right)$ & $\Delta \mathrm{S}\left(\mathrm{j} \mathrm{mol}{ }^{-1} \mathrm{~T}^{-1}\right)$ \\
\hline 7.4 & 296 & 0.9929 & -36.43 & 6.57 & -100.56 \\
& 298 & 0.9974 & & 6.37 \\
& 300 & 0.9945 & & 6.17 \\
& 302 & 0.9966 & 5.97 & \\
\hline
\end{tabular}

a) $\mathrm{R}$ is the linear quotiety.

\section{Conclusions}

The interaction study of drugs with proteins have great importance in molecular biology, biochemistry, pharmacy, and pharmacology. Our study shows that fluorescence spectroscopy can be very useful in investigating the molecular interactions between drugs and HSA. From the fluorescence measurements, the binding constant and binding ratio allowed to be measured. Thermodynamic parameters related to the interaction were also estimated by using fluorescence spectroscopy. In this study, the binding of ornidazole to human serum albumin was evaluated by fluorescence measurements. The result indicated that ornidazole interacted with HSA by a static quenching procedure. The reaction between HSA and OR which occurs via van der Waals interactions and hydrogen bonds is energy dependent.

This study indicated that interaction between drugs and proteins can be studied by the fluorescence quenching technique. This technique may give us a better understanding of pharmacokinetics such as distribution of a drug, drug metabolism, and the dosage in therapeutics in vitro. Particularly, the study on the binding sites of proteins will help to synthesize new drugs and to find their targets in the human body as a specific task. Further studies on protein binding of drugs similar molecules will be in progress in our laboratory.

\section{Acknowledgments}

We would like to thank The Research Foundation of Selcuk University (Project No: 18401073) for financial support of this work.

\section{References}

[1] Luo, H., Du, Y., Guo, ZX. (2009). Electrochemistry of N-n-undecyl-N'-(sodium-p aminobenzenesulfonate) thiourea and its interaction with bovine serum albumin. Bioelectrochemistry, 4: 232-235. https://doi.org/10.1016/j.bioelechem.2008.10.004.

[2] Banerjee, M., Pal, U., Subudhhi, A., Chakrabarti, A., Basu, S. (2012). Interaction of Merocyanine 540 with serum albumins: photophysical and binding studies. Journal of Photochemistry Photobiology B Biology, 108: 23-33. https://doi.org/10.1016/j.jphotobiol.2011.12.005.

[3] He, X.M. Carter, D.C. (1992). Atomic structure and chemistry of human serum albumin. Nature, 358: 209-215. https://doi.org/10.1038/358209a0.

[4] Sevilla, P., Rivas, J.M., García-Blanco, F., García-Ramos, J.V., Sánchez-Corté, S. (2007). Identification of the antitumoral drug emodin binding sites in bovine serum albumin by spectroscopic methods. Biochimica Biophysica Acta, 1774: 1359-1369. https://doi.org/10.1016/j.bbapap.2007.07.022.

[5] Carter, D., Ho, J.X. (1994). In Advances in Protein Chemistry (Anfinsen CB, Edsall JT, Richards FM, and Eisenberg DS, eds.), vol. 45, Academic Press, New York: 153-203.

[6] Peters, T. Advances in Protein Chemistry. vol. 37, Academic Press, New York: 161-245 (a); Tayeh N, Rungassamy T, Albani JR. 2009. J Pharmaceutical Biomedical Analysis 1985, 50: 107-116 (b). https://doi.org/10.1016/j.jpba.2009.03.015.

[7] Tsujino, I., Anderson, G.S., Sieber, F. (2001). Postirradiation hyperthermia selectively potentiates the merocyanine 540-sensitized photoinactivation of small cell lung cancer cells. Photochemistry Photobiology, 73: 191-198. https://doi.org/10.1562/0031-8655(2001)073<0191:PHSPTM>2.0.CO;2.

[8] Ghoneim, M.M., El-Desoky, H.S., Abdel-Galeil, M.M. (2011). Electrochemistry of the antibacterial and antifungal drug nitroxoline and its determination in bulk form, pharmaceutical formulation and human blood. Bioelectrochemistry, 80:162-168. https://doi.org/10.1016/j.bioelechem.2010.08.003.

[9] Fotouhi L, Banafsheh S, Heravi MM. (2009). Electrochemistry of the interaction of furazolidone and bovine serum albumin. Bioelectrochemistry, 77: 26-30. https://doi.org/10.1016/j.bioelechem.2009.05.011.

[10] Otto, J., Lesko, L.J. (1986). Protein binding of nifedipine. Journal of Pharmacy Pharmacology, 38(5): 399-400. https://doi.org/10.1111/j.20427158.1986.tb04598.x.

[11] Guo, Q.L., Li, R., Zhou, X., Liu, Y. (2008). Study on the interaction of ketoconazole with human and bovine serum albumins by fluorescence spectroscopy. Chinese Journal of Chemistry, 26(12): 2207-2215. https://doi.org/10.1002/cjoc.200890393.

[12] Zhang, Q., Nia, Y., Kokot, S. (2012). Combined voltammetric and spectroscopic analysis of small molecule-biopolymer interactions: The levodopa and serum albumin system. Talanta, 15(88): 524-532. https://doi.org/10.1016/j.talanta.2011.11.027.

[13] Ravera, M., Gabano, E., Baracco, S., Osella, D. (2009). Electrochemical evaluation of the interaction between antitumoral titanocene dichloride and biomolecules. Inorganica Chimica Acta, 362: 1303-1306. https://doi.org/10.1016/j.ica.2008.06.022.

[14] Nayar, S., Mir, A., Ashok, A., Guha, A. and Sharma, V. (2010). Bovine Serum Albumin Binding and Drug Delivery Studies with PVA-Ferrofluid. Journal of Bionic Engineering, 7: 29-34. https://doi.org/10.1016/S1672-6529(09)60188-8.

[15] Bi, S., Sun, Y., Qiao, C., Zhang, H., Liu, C.(2009). Binding of several anti-tumor drugs to bovine serum albumin: Fluorescence study. Journal of Luminescence, 129: 541-547. https://doi.org/10.1016/j.jlumin.2008.12.010.

[16] Hu, Y.J., Liu, Y., Shen, X.S., Fang, X.Y., Qu, S.S. (2005). Studies on the interaction between 1-hexylcarbamoyl-5-fluorouracil and bovine serum albumin. Journal of Molecular Structure 738: 143-147. https://doi.org/10.1016/j.molstruc.2004.11.062.

[17] Erkkola, R., Järvinen, H. (1987). Single dose of ornidazole in the treatment of bacterial vaginosis. Annales Chirurgiae et Gynaecologiae, $202: 94-$ 96.

[18] Pradeep, A.R., Kalra, N., Priyanka, N., Naik, S.B. (2012). Microbiological outcomes of systemic ornidazole use in chronic periodontitis. Part II Journal of the International Academy of Periodontology, 14(2): 50-54.

[19] Grewal, A.S., Bhardwaj, S.K., Patro, S.K., Kanungo, S.K. (2012). Visible spectrophotometric estimation of ornidazole in pure and pharmaceutical formulation. International Journal of Chemical Technology Research, 4(3): 1044-1048.

[20] Asane, G.S., Rao, Y.M., Bhatt, J.H., Shaikh, K.S. (2011). Optimization, characterisation and pharmacokinetic studies of mucoadhesive oral multiple unit systems of ornidazole. Scientia Pharmaceutica, 79(1): 181-196. https://doi.org/10.3797/scipharm.1003-03.

[21] Wei, T.-T., Sun, J.-H., Han L.-W., Chen K., Wang Z.-Q., Ji, H. (2015). Effects of the ornidazole enantiomers on the central nervous system: Involvement of the GABAA receptor, Chemical Biology Interactions, 5(242): 163-9 https://doi.org/10.1016/j.cbi.2015.09.019.

[22] Zhang, L.N., Wu, F.Y., Liu, A.H. (2011). Study of the interaction between 2,5-di-[2-(4-hydroxy-phenyl)ethylene]-terephthalonitril and bovine serum albumin by fluorescence spectroscopy. Spectrochimica Acta Part A 79: 97-103. https://doi.org/10.1016/j.saa.2011.02.013.

[23] Lakowicz, J.R. (2006). Principles of Fluorescence Spectroscopy, third ed, Springer press, New York https://doi.org/10.1007/978-0-387-46312-4

[24] Yang, J., Jing, Z.H., Jie, J.J., Guo, P. (2009). Fluorescence spectroscopy study on the interaction between Gossypol and bovine serum albumin. Journal of Molecular Structures, 920: 227-230. https://doi.org/10.1016/j.molstruc.2008.10.053. 
[25] Han, X.L., Mei, P., Liu, Y., Xiao, Q., Jiang, F.L., Li, R. (2009). Binding interaction of quinclorac with bovine serum albumin: A biophysical study. Spectrochimica Acta A, 74: 781-787. https://doi.org/10.1016/j.saa.2009.08.018.

[26] Li, Y., Yang, G.Z., Mei, Z. (2012). Spectroscopic and dynamic light scattering studies of the interaction between pterodontic acid and bovine serum albumin. Acta Pharmaceutica Sinica B, 2(1): 53-59. https://doi.org/10.1016/j.apsb.2011.12.001.

[27] Zhang, G., Chen, X., Guo, J., Wang, J. (2009). Spectroscopic investigation of the interaction between chrysin and bovine serum albumin. Journal of Molecular Structures, 921: 346-51. https://doi.org/10.1016/j.molstruc.2009.01.036.

[28] Tong, J.Q., Zhang, H.X., Yang, H.M., Mei, P. (2010). Photochemical studies on the binding of an organic fluoride to bovine serum albumin. Molec ular Biology Reports, 37: 1741-1747. https://doi.org/10.1007/s11033-009-9598-Z

[29] Yu, J.H., Li, B., Dai, P., Ge, S.G. (2009). Molecular simulation of the interaction between novel type rhodanine derivative probe and bovine serum albumin. Spectrochimica Acta A, 74: 277-281. https://doi.org/10.1016/j.saa.2009.06.013.

[30] Maltas, E. (2014). Interactions of nicleasmide with serum proteins. Journal of Food Drug Analysis, 22: 549-555. https://doi.org/10.1016/j.jfda.2014.03.004. 